\title{
Hypertension among newly diagnosed diabetic patients at Mulago National Referral Hospital in Uganda: a cross sectional study
}

\author{
Martin Muddu, Edrisa Mutebi, Isaac Ssinabulya, Samuel Kizito, Charles Kiiza Mondo
}

\begin{abstract}
Background: The prevalence of hypertension in patients with diabetes is approximately two-fold higher than in age-matched subjects without the disease and, conversely, individuals with hypertension are at increased risk of developing diabetes compared with normotensive persons. Up to $75 \%$ of cases of cardiovascular disease (CVD) in patients with diabetes are attributed to hypertension. Diabetics who have hypertension are more likely to develop complications and die, and appropriate blood pressure control in these individuals reduces the risk. This study sought to determine the prevalence and factors associated with hypertension among newly diagnosed adult diabetic patients in a national referral hospital in Uganda.

Methods: In this cross-sectional study, conducted between June 2014 and January 2015, we recruited 201 newly diagnosed adult diabetic patients. Information on patients' socio-demographics was obtained using a pre-tested questionnaire, while biophysical profile, blood pressure measurement, biochemical testing and echocardiographic findings were obtained by the research team for all the participants. Bivariate and multivariate logistic regression analyses were used to investigate the association of several factors with hypertension.

Results: Of the 201 patients recruited, 102 were male (50.8\%) and the mean age was $46 \pm 15$ years. The majority of patients (159) had type 2 diabetes mellitus (DM) $(79.1 \%)$ with a mean $\mathrm{HbA}_{\mathrm{lc}}$ level of $13.9 \pm 5.3 \%$. The prevalence of hypertension was $61.9 \%$ (95\% CI: $54.8-68.6 \%)$. Knowledge of hypertension status was at $56(27.7 \%)$ patients, $24(44.4 \%)$ hypertensives were on treatment, and $19(33.9 \%)$ were using ACE inhibitors/angiotensin receptor blockers. The independent factors associated with hypertension were being employed (OR 0.37 , 95\% CI: $0.16-0.90, p=0.029)$ and being overweight or obese (OR 11.6, 95\% CI: 4.29-31.2, $p<0.0001$ ).

Conclusion: The prevalence of hypertension was high in this population of newly diagnosed diabetics, few patients had knowledge of their hypertension status and few were on appropriate treatment. Both modifiable and non-modifiable risk factors were associated with hypertension in this group. Therefore routine assessment, treatment and control of hypertension among diabetics is necessary to prevent cardiovascular complications and death. There is also a need to address the modifiable risk factors.
\end{abstract}

Department of Medicine, College of Health Sciences, Makerere University, Mulago Hospital Complex, Mulago, Uganda Martin Muddu, MB ChB, MMed, muddu.martin@gmail.com Edrisa Mutebi, MB ChB, MSc, MMed Isaac Ssinabulya,MB ChB, MMed

Charles Kiiza Mondo, MB ChB, MMed, PhD

Clinical Epidemiology Unit, College of Health Sciences, Makerere University, Mulago, Uganda

Samuel Kizito, MB ChB, MSc
Keywords: hypertension, newly diagnosed, diabetes, Uganda

Submitted 21/5/16, accepted 5/3/18

Published online 20/4/18

Cardiovasc J Afr 2018; 29: 218-224

www.cvja.co.za

DOI: $10.5830 / \mathrm{CVJA}-2018-015$

The burden of non-communicable diseases (NCDs) is increasing rapidly in sub-Saharan Africa. ${ }^{1}$ It is anticipated that NCDs may account for $46 \%$ of deaths in sub-Saharan Africa by 2030 , compared to $28 \%$ in $2008 .{ }^{1}$ Hypertension and diabetes mellitus (DM) are of particular concern; however, precise epidemiological data are rare. ${ }^{1-4}$ One of the commonest NCDs experienced during this early stage of the epidemiological transition is hypertension. It is predicted that more than 125 million adults in sub-Saharan Africa alone will have hypertension by $2025,,^{5,6}$ and in Uganda, hypertension is the most reported NCD. ${ }^{7-10}$

Increasing urbanisation and associated lifestyle changes as well as improvements in life expectancy have contributed to a surge in NCDs, including hypertension. ${ }^{1,5}$ Likewise, the prevalence of DM is on a rise in sub-Saharan Africa and will more than double by $2025 .{ }^{11}$

The prevalence of hypertension in patients with diabetes is approximately two-fold higher than in age-matched subjects without the disease, ${ }^{12-14}$ and conversely, individuals with hypertension are at increased risk of developing diabetes compared with normotensive persons. Furthermore, up to $75 \%$ of cases of cardiovascular disease (CVD) in patients with diabetes can be attributed to hypertension. ${ }^{15}$ CVD, especially stroke, accounts for up to $80 \%$ of all deaths in the diabetic population and three-quarters of these deaths occur in sub-Saharan Africa. ${ }^{16,17}$

The high burden of hypertension in diabetics has led to an increase in the risk and prevalence of cardiac abnormalities in diabetes..$^{18}$ Also, life expectancy in sub-Saharan Africa has risen in the past 50 years. Many more people living with diabetes are therefore exposed to the risk of hypertension for long periods for the complications to develop and for them to experience the clinical syndromes of CVD. ${ }^{19}$

Diabetics who have hypertension are more likely to develop complications and die, and appropriate blood pressure control in these individuals reduces the risk. The lower the systolic blood pressure, the lower the risk of complications. ${ }^{12}$ There is an additional risk reduction with angiotensin converting enzyme inhibitors (ACE inhibitors) and $\beta$-blockers over and above that associated with lowering of blood pressure. ${ }^{12}$

In patients with type $2 \mathrm{DM}$, hypertension is associated with left ventricular hypertrophy ( $\mathrm{LVH}),{ }^{20,21}$ which is an independent 
predictor of cardiovascular events in hypertensive patients with diabetes. ${ }^{22}$ Hypertension is also a major risk factor for myocardial infarction and stroke,,$^{12,23,24}$ and indeed hypertension is the leading risk factor for mortality worldwide. ${ }^{5,25-28}$ Additionally, hypertension is a major causal factor of end-stage kidney failure, blindness and non-traumatic amputation in people with diabetes, where attributable risks are 50,35 and $35 \%$, respectively. ${ }^{16}$

Unfortunately the majority of people with hypertension in sub-Saharan Africa do not know they have it, and most are not on treatment. This reflects the low level of knowledge of the dangers of untreated hypertension in this population. ${ }^{10}$

In sub-Saharan Africa there is still a lack of awareness about the growing problem of NCDs, which, unfortunately, is often coupled with the absence of a clear policy framework for prevention and management. ${ }^{7}$ Given the long-term decreased productivity associated with hypertension among diabetics, identifying and treating a large proportion of patients has the potential to generate tremendous social and economic benefits in this region. ${ }^{5,29-31}$

In this study we sought to determine the prevalence and factors associated with hypertension among newly diagnosed adult diabetic patients in a national referral hospital in Uganda. These findings are not only necessary, but also contribute to the diagnosis and management of DM and hypertension in sub-Saharan Africa.

\section{Methods}

This study was carried out in the diabetes out-patient clinic, the medical endocrine ward and the medical emergency ward of Mulago National Referral Hospital. It is the only national referral hospital for Uganda and is the teaching hospital for Makerere University, with a bed capacity of 1 500. Mulago Hospital receives referrals from all parts of the country including from neighbouring countries such as Southern Sudan, the Democratic Republic of Congo and Rwanda. The study population is representative of the Ugandan diabetic population.

This was a cross-sectional study among 201 newly diagnosed diabetic patients at Mulago Hospital in Uganda, conducted between June 2014 and January 2015. All newly diagnosed diabetic patients aged 18 years and above attending the diabetes clinic or admitted to the medical wards of Mulago Hospital during the study period, who met the inclusion criteria and provided informed consent, were recruited consecutively. We excluded patients with urinary tract infection in order to avoid confounding in microalbuminuria, and those who were unable to provide the necessary information. Fig. 1 illustrates the patient recruitment flow.

Institutional consent was sought from the Department of Medicine, Makerere University, Mulago National Referral Hospital and the School of Medicine research and ethics committee of Makerere University College of Health Sciences. All study participants provided written informed consent for involvement in the study. Enrolment was totally free and voluntary, and participants were free to withdraw at any time without any consequences. The patients' records/information was anonymised and de-identified prior to analysis.

We took a focused history and performed a specific physical examination to determine biophysical measurements. Information gathered was entered into a pre-tested questionnaire. We assessed the following factors: patients' demographic data, history of hypertension, age, physical exercise at work and leisure, marital status, date of diagnosis of DM, drug history, occupation, education level and last normal menstrual period.

Body mass was measured to the nearest kilogram using a Secco weighing scale, height was measured in metres using a non-stretchable tape, and these were used to compute body mass index (BMI). Waist and hip circumferences were measured and waist-to-hip ratios were determined for all patients.

Glycated haemoglobin $\left(\mathrm{HbA}_{1 \mathrm{c}}\right)$ was measured by automated high-performance liquid chromatography. Other investigations included urinalysis and microalbuminuria using albumin-tocreatinine ratio.

Echocardiography parameters were acquired using a commercially available machine, Phillips HD11XE (Eindhoven, the Netherlands), with two-dimensional, M-mode and Doppler capabilities. It was used according to the American Society of Echocardiography guidelines. ${ }^{32}$

Blood pressure was measured using a mercury sphygmomanometer, according to the American Heart Association guidelines for the auscultatory method of blood pressure assessment. ${ }^{33}$ The degree of precision of blood pressure measurement in this study was $\pm 2 \mathrm{mmHg} .{ }^{33}$ Hypertension was defined as present if subjects were on anti-hypertensive medication, had a history of hypertension and/or evidence of hypertension (blood pressure $\geq 140 / 90 \mathrm{mmHg}$ ).

\section{Statistical analysis}

Data were double entered in a database developed with Epidata version 3.1, validated, and inconsistences were cleared. The data were then exported to Stata 13 for analysis. Continuous data were summarised using measures of central tendency while categorical data were summarised as frequencies and percentages and presented in tables. Prevalence was presented as percentages

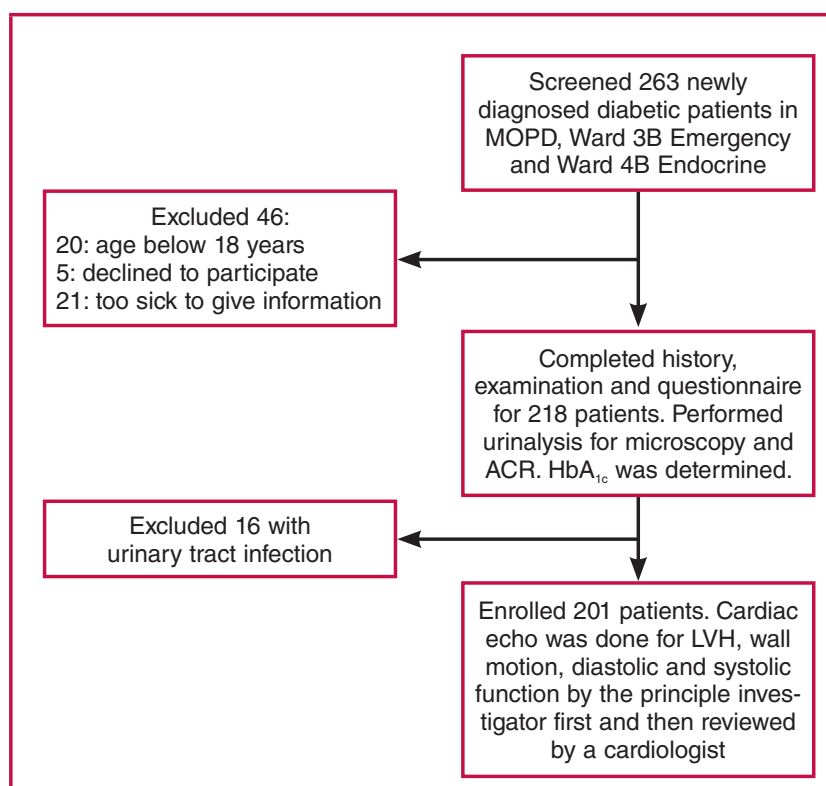

MOPD: Mulago out-patient department, ACR: albumin-to-creatinine ratio, $\mathrm{HbA}_{1 \mathrm{c}}$ : glycated haemoglobin, $\mathrm{LVH}$ : left ventricular hypertrophy.

Fig. 1. Patient flow chart. 
with their confidence intervals. Comparisons were made using the Student's $t$-test for continuous data and chi-squared or Fisher's exact test for categorical data.

The outcome was dichotomised as patients having hypertension or not, then logistic regression was used to determine the association between the predictors and hypertension. This was presented as odds ratio (OR) and their $95 \%$ confidence interval (CI). Only factors with a $p$-value $<0.2$ at bivariate analysis were considered for multivariate analysis. Multivariate logistic regression was performed and interaction was assessed for with the Chunk test. Confounding was assessed for using a $10 \%$ difference between the crude and adjusted models. Significance was at $p \leq 0.05$.

\section{Results}

This study recruited 201 newly diagnosed diabetic patients between June 2014 and January 2015. Of these, 102 (50.8\%) were males. The mean age of the participants was $46 \pm 15$ years (Table 1). Patients with type 1 and type $2 \mathrm{DM}$ had mean ages of $25.6(18-42)$ and $51.9(26-90)$ years, respectively. The majority of patients had type $2 \mathrm{DM}(n=159,79.1 \%)$ and the rest had type 1 $\mathrm{DM}(n=42,20.9 \%)$ (Table 2). The mean $\mathrm{HbA}_{1 \mathrm{c}}$ was $13.9 \pm 5.3 \%$. Mean duration of diabetes was two months. The majority of patients $(124,62.0 \%)$ were unemployed.

Blood pressure assessment was performed on all 201 participants and the results are shown in Table 3. Prevalence of hypertension was 61.9\% (95\% CI: 54.8-68.6\%). Systolic hypertension was present in $104(51.5 \%)$ participants $(95 \%$ CI: $45.3-59.2 \%$ ) while diastolic hypertension was present in 92 (45.5\%) (95\% CI: 39.3-53.2\%). Among those who were hypertensive, only $56(27.7 \%)$ knew that they were hypertensive, and among these, only $24(44.4 \%)$ were on treatment for hypertension. The use of either ACE inhibitors or angiotensin receptor blockers (ARBs) among those who knew their hypertension status was only $19(33.9 \%)$ subjects.

\begin{tabular}{|c|c|c|c|c|}
\hline Characteristics & $\begin{array}{c}\text { Total } \\
\text { (n) }\end{array}$ & $\begin{array}{c}\text { Total } \\
(\%)\end{array}$ & $\begin{array}{c}\text { Hypertensive } \\
\mathrm{n}(\%)\end{array}$ & $\begin{array}{c}\text { Normotensive } \\
\mathrm{n}(\%)\end{array}$ \\
\hline \multicolumn{5}{|l|}{ Age } \\
\hline$<40$ years & 58 & 28.9 & $21(36.2)$ & $37(63.8)$ \\
\hline$>40$ years & 143 & 71.1 & $105(73.4)$ & $38(26.6)$ \\
\hline \multicolumn{5}{|l|}{ Gender } \\
\hline Male & 102 & 50.8 & $54(52.9)$ & $48(47.1)$ \\
\hline Female & 99 & 49.3 & $72(72.7)$ & $27(27.3)$ \\
\hline \multicolumn{5}{|l|}{ Employment } \\
\hline Employed & 76 & 38.0 & $41(53.9)$ & $35(46.1)$ \\
\hline Unemployed & 124 & 62.0 & $85(68.6)$ & $39(31.4)$ \\
\hline \multicolumn{5}{|l|}{ Pregnancy } \\
\hline Yes & 6 & 5.4 & $3(50.0)$ & $3(50.0)$ \\
\hline No & 105 & 94.6 & $74(70.5)$ & $31(29.5)$ \\
\hline \multicolumn{5}{|l|}{ Education } \\
\hline None & 17 & 8.5 & $10(58.8)$ & $7(41.2)$ \\
\hline Primary & 78 & 38.8 & $50(64.1)$ & $28(35.9)$ \\
\hline Secondary & 75 & 37.3 & $45(60.0)$ & $30(40.0)$ \\
\hline Tertiary & 31 & 15.4 & $21(67.7)$ & $10(32.3)$ \\
\hline \multicolumn{5}{|l|}{ Marital status } \\
\hline Never married & 29 & 14.4 & $7(24.1)$ & $22(75.9)$ \\
\hline Currently married & 119 & 59.2 & $83(69.8)$ & $36(30.3)$ \\
\hline No longer married & 53 & 26.4 & $36(67.9)$ & $17(32.1)$ \\
\hline
\end{tabular}

\begin{tabular}{|c|c|c|c|c|}
\hline Characteristic & $\begin{array}{l}\text { Total } \\
\text { (n) }\end{array}$ & $\begin{array}{l}\text { Total } \\
(\%)\end{array}$ & $\begin{array}{c}\text { Hypertensive } \\
\mathrm{n}(\%)\end{array}$ & $\begin{array}{c}\text { Normotensive } \\
\mathrm{n}(\%)\end{array}$ \\
\hline \multicolumn{5}{|c|}{ Physical activity at work } \\
\hline Sedentary & 25 & 12.4 & $16(69.6)$ & $7(30.4)$ \\
\hline Mild & 51 & 25.3 & $33(64.7)$ & $18(35.3)$ \\
\hline Moderate & 82 & 40.6 & $54(66.7)$ & $27(33.3)$ \\
\hline Strenuous & & & $22(50.0)$ & $22(50.0)$ \\
\hline Does not work & 44 & 21.8 & $1(50.0)$ & $1(50.0)$ \\
\hline \multicolumn{5}{|c|}{ Physical activity at leisure } \\
\hline Sedentary & 142 & 71.0 & $96(67.6)$ & $46(32.4)$ \\
\hline Moderate & 58 & 29.0 & $29(50.0)$ & $29(50.0)$ \\
\hline \multicolumn{5}{|l|}{ DM type } \\
\hline Type 1 & 42 & 20.9 & $11(26.2)$ & $31(73.8)$ \\
\hline Type 2 & 159 & 79.1 & $115(72.3)$ & $44(27.7)$ \\
\hline \multicolumn{5}{|c|}{ Microalbumin in urine } \\
\hline Absent & 79 & 44.9 & $50(62.5)$ & $30(37.5)$ \\
\hline Present & 97 & 55.1 & $58(61.1)$ & $37(38.3)$ \\
\hline \multicolumn{5}{|l|}{ BMI } \\
\hline Underweight & 39 & 19.4 & $10(25.6)$ & $29(74.4)$ \\
\hline Normal weight & 75 & 37.3 & $40(53.3)$ & $35(46.7)$ \\
\hline Over weight & 3 & 1.5 & $1(33.3)$ & $2(66.7)$ \\
\hline Obesity & 84 & 41.8 & $75(89.3)$ & $9(10.7)$ \\
\hline \multicolumn{5}{|l|}{ Waist:hip ratio } \\
\hline Normal & 141 & 69.8 & $81(57.9)$ & $59(42.1)$ \\
\hline Abnormal & 61 & 30.2 & $45(73.8)$ & $16(26.2)$ \\
\hline \multicolumn{5}{|l|}{$\mathrm{HbA}_{\mathrm{lc}}(\%)$} \\
\hline$<7 \%$ & 15 & 8.4 & $11(73.3)$ & $4(26.7)$ \\
\hline$>7 \%$ & 164 & 91.6 & $101(61.9)$ & $62(38.0)$ \\
\hline \multicolumn{5}{|c|}{ Ejection fraction $(\%)$} \\
\hline$>50 \%$ & 158 & 78.2 & $102(64.6)$ & $56(35.4)$ \\
\hline$<50 \%$ & 44 & 21.8 & $24(55.8)$ & $19(44.2)$ \\
\hline \multicolumn{5}{|l|}{ LVH } \\
\hline Present & 39 & 19.3 & $89(77.4)$ & $26(26.5)$ \\
\hline Absent & 163 & 80.7 & $37(43.0)$ & $49(56.9)$ \\
\hline \multicolumn{5}{|l|}{ Diastolic function } \\
\hline Normal & 91 & 45.1 & $44(48.9)$ & $46(51.1)$ \\
\hline Impaired & 111 & 54.9 & $82(73.9)$ & $29(26.1)$ \\
\hline \multicolumn{5}{|l|}{ Wall motion } \\
\hline Normal & 193 & 96.5 & $120(62.2)$ & $73(37.8)$ \\
\hline Abnormal & 7 & 3.5 & $5(71.4)$ & $2(28.6)$ \\
\hline
\end{tabular}

For participants who knew their hypertension status, the majority 44 (77.2) had been hypertensive for less than five years. The number who had been hypertensive for durations between five and 10 years and more than 10 years were eight (4.3\%) and five $(8.8 \%)$, respectively.

In bivariate analysis, the factors associated with hypertension included: female gender, age above 40 years, participants who

Table 3. Prevalence, knowledge and treatment of hypertension among 201 newly diagnosed diabetic patients at Mulago Hospital

\begin{tabular}{lccc}
\hline Parameters & Number & Prevalence (\%) & $95 \%$ CI \\
Hypertension & 125 & 61.9 & $54.8-68.6$ \\
Systolic BP > $140 \mathrm{mmHg}$ & 104 & 51.5 & $45.3-59.2$ \\
Diastolic BP > 90 mmHg & 92 & 45.5 & $39.3-53.2$ \\
Knowledge of hypertension & 56 & 27.7 & $22.1-34.6$ \\
HTN newly diagnosed & 69 & 34.2 & $27.6-39.8$ \\
ACEI/ARB use in known HTN & 19 & 33.9 & $26.7-39.2$ \\
Known HTN on drugs & 24 & 44.4 & $38.9-52.4$ \\
Known HTN not on drugs & 30 & 55.6 & $47.2-62.1$ \\
HTN: hypertension, ACEI: ace inhibitor, ARB: angiotensin receptor blocker.
\end{tabular}


were employed, participants who were never married and those who were currently married, overweight and obesity, increase in waist:hip ratio, LVH and diastolic dysfunction (Table 4). After adjusting for the patients' gender, age, employment, marital status, BMI, waist:hip ratio, $\mathrm{LVH}$ and diastolic dysfunction, the only significant factors associated with hypertension were being employed (OR 0.37, 95\% CI: $0.16-0.90, p=0.029$ ), and overweight and obesity (OR 11.6, 95\% CI: 4.29-31.2, $p<0.0001$ ).

\section{Discussion}

The prevalence of hypertension among newly diagnosed diabetics was high in this group, with more than six patients out of 10 having hypertension. This is in keeping with earlier studies, which found that the prevalence of hypertension in patients with diabetes was approximately two-fold higher than in age-matched subjects without the disease, ${ }^{12-14}$ and conversely, individuals with hypertension were at increased risk of developing diabetes compared with normotensive persons. ${ }^{15}$

In Uganda, the prevalence of hypertension among non-diabetics ranges between 20 and 35\%, with a higher prevalence in the urban areas. ${ }^{10,34-37}$ This is consistent with evidence from other parts of sub-Saharan Africa that indicated the prevalence of hypertension was between 20 and $50 \%{ }^{7,35,37-40}$ Therefore, the prevalence we found of $62 \%$ in diabetic subjects is approximately twice the current prevalence of hypertension in non-diabetic patients in Uganda.

Unfortunately only one-quarter of all those who are hypertensive know their status, and this is evident from other studies in the region, which found that the majority of patients with hypertension in sub-Saharan Africa did not know they were hypertensive and very few were on treatment, yet hypertension is the leading cause of stroke in Africa. In another cross-sectional study in Uganda, awareness of hypertension was low, at less than $30 \%{ }^{7}$

This low awareness could be explained by the fact that only $27.8 \%$ of the population ever has their blood pressure measured in Uganda. Awareness of hypertension largely depends on the capacity of the health system to provide diagnostic services for hypertension to the general population..$^{40}$ Unfortunately, the healthcare system in Uganda is largely constrained by communicable diseases and NCDs have not received the attention they deserve. ${ }^{7}$ In order to increase awareness, there is a need to screen all adults at an appropriate opportunity when they come into contact with the health system. This could even be done through outreaches and community programmes. ${ }^{7,41,42}$

\begin{tabular}{|c|c|c|c|c|c|c|}
\hline \multirow[b]{2}{*}{ Factors } & \multicolumn{2}{|c|}{ Hypertension } & \multirow[b]{2}{*}{ Crude OR $(95 \%$ CI $)$} & \multirow[b]{2}{*}{ p-value } & \multirow[b]{2}{*}{ Adjusted OR $(95 \%)$} & \multirow[b]{2}{*}{$\mathrm{p}$-value } \\
\hline & Absent, $\mathrm{n}(\%)$ & Present, n (\%) & & & & \\
\hline \multicolumn{7}{|l|}{ Gender } \\
\hline Male & $48(47.1)$ & $54(52.9)$ & 1 & & & \\
\hline Female & $27(27.3)$ & $72(72.7)$ & $2.37(1.32-4.27)$ & 0.004 & & \\
\hline \multicolumn{7}{|l|}{ Age } \\
\hline$<40$ years & $37(63.8)$ & $21(36.2)$ & 1 & & 1 & \\
\hline$>40$ years & $38(26.6)$ & $105(73.4)$ & $4.87(2.54-9.34)$ & $<0.0001$ & $2.49(0.62-9.95)$ & 0.197 \\
\hline \multicolumn{7}{|l|}{ Employment } \\
\hline Unemployed & $39(31.5)$ & $85(68.6)$ & 1 & & 1 & \\
\hline Employed & $35(46.1)$ & $41(53.9)$ & $0.54(0.30-0.97)$ & 0.039 & $0.37(0.16-0.90)$ & 0.029 \\
\hline \multicolumn{7}{|l|}{ Marital status } \\
\hline No longer married & $17(32.1)$ & $36(67.9)$ & 1 & & 1 & \\
\hline Never married & $22(75.9)$ & $7(24.1)$ & $7.25(2.84-18.5)$ & $<0.0001$ & $2.86(0.69-11.9)$ & 0.149 \\
\hline Currently married & $36(30.3)$ & $83(69.8)$ & $6.66(2.38-18.6)$ & $<0.0001$ & $1.37(0.28-6.63)$ & 0.703 \\
\hline \multicolumn{7}{|l|}{$\mathrm{HbA}_{\mathrm{lc}}$} \\
\hline Normal & $4(26.7)$ & $11(73.3)$ & 1 & & & \\
\hline Abnormal & $62(38.0)$ & $101(61.9)$ & $0.59(0.18-1.94)$ & 0.387 & & \\
\hline \multicolumn{7}{|l|}{ Microalbuminuria } \\
\hline Normal & $30(37.5)$ & $50(62.5)$ & 1 & & & \\
\hline Abnormal & $37(38.3)$ & $58(61.1)$ & $0.94(0.51-1.74)$ & 0.844 & & \\
\hline \multicolumn{7}{|l|}{ BMI } \\
\hline Normal weight & $66(56.4)$ & $51(43.6)$ & 1 & & 1 & \\
\hline Overweight, obesity & $9(10.7)$ & $75(89.3)$ & $10.8(4.9-23.6)$ & $<0.0001$ & $11.6(4.29-31.2)$ & $<0.0001$ \\
\hline \multicolumn{7}{|l|}{ Waist:hip ratio } \\
\hline Normal & $59(42.1)$ & $81(57.9)$ & 1 & & 1 & \\
\hline Abnormal & $16(26.2)$ & $45(73.8)$ & $2.05(1.06-3.97)$ & 0.034 & $1.03(0.39-2.73)$ & 0.949 \\
\hline \multicolumn{7}{|l|}{ Ejection fraction } \\
\hline$>50 \%$ & $56(35.4)$ & $102(64.6)$ & 1 & & & \\
\hline$<50 \%$ & $19(44.2)$ & $24(55.8)$ & $0.69(0.35-1.38)$ & 0.295 & & \\
\hline \multicolumn{7}{|l|}{ LVH } \\
\hline Absent & $49(56.9)$ & $37(43.0)$ & 1 & & 1 & \\
\hline Present & $26(26.5)$ & $89(77.4)$ & $4.53(2.46-8.35)$ & $<0.0001$ & $1.97(0.88-4.38)$ & 0.098 \\
\hline \multicolumn{7}{|l|}{ Diastolic function } \\
\hline Normal & $46(51.1)$ & $44(48.9)$ & 1 & & 1 & \\
\hline Impaired & $29(26.1)$ & $82(73.9)$ & $2.96(1.64-5.34)$ & $<0.0001$ & $0.94(0.40-2.18)$ & 0.885 \\
\hline
\end{tabular}


Furthermore, among those who knew they had hypertension, less than half were on treatment. This is similar to what earlier studies found, and this carries a great risk for the complications of diabetes, especially CVDs such as stroke, LVH, myocardial infarction, as reported by the United Kingdom Prospective Diabetes Study (UKPDS). In one cross-sectional study among people with hypertension in Uganda, less than $10 \%$ were controlled. In another retrospective study conducted in an urban diabetes clinic in Kampala, optimal blood pressure control, defined as $\leq 140 / 80 \mathrm{mmHg}$, was noted in $56 \%$ of the patients. ${ }^{43}$ This corroborates the notion that blood pressure control among adult diabetic patients in Uganda is sub-optimal. This calls for the development and implementation of local guidelines to improve diabetes care and minimise complications due to hypertension. ${ }^{43}$

Possible reasons for this very low level of control may be that the majority of people with hypertension are not aware they have the condition, and even among those who are aware, less than half are receiving treatment. However, even among those receiving treatment, only one in three achieve blood pressure control. A worrying global trend is that low levels for the control of hypertension are widespread in both low- and high-income countries. ${ }^{7,40,44,45}$

There is an additional risk reduction with ACE inhibitors and $\beta$-blockers over and above that associated with lowering of blood pressure among diabetics. ${ }^{12}$ However, the use of ACE inhibitors/ ARBs among those who knew their status was in only one-third of all participants, yet we know that ACE inhibitors reduce the risk for nephropathy and other complications of diabetes, such as LVH. For this reason, the $\mathrm{JNC} 7$ and $\mathrm{JNC} 8$ recommend that every diabetic who has hypertension must be started on ACE inhibitors/ARBs among other treatment options. ${ }^{46}$

In patients with type $2 \mathrm{DM}$, hypertension is associated with LVH. ${ }^{20,21}$ According to the Appropriate Blood Pressure Control in Diabetes (ABCD) trial, $\mathrm{LVH}$ is an independent predictor of cardiovascular events in hypertensive patients with diabetes. ${ }^{22}$ Hypertension is also a major risk factor for myocardial infarction and stroke, ${ }^{12,23,24}$ and indeed it is the leading risk factor for mortality worldwide. ${ }^{5,25-27}$ Therefore prevention and control of hypertension are critical in reducing morbidity and mortality attributable to cardiovascular diseases among diabetics.

According to the UKPDS, the incidence of clinical complications among diabetics is significantly associated with systolic blood pressure, except for cataract extraction. Each $10 \mathrm{mmHg}$ decrease in updated mean systolic blood pressure is associated with risk reductions of $12 \%$ for any complication related to diabetes, $15 \%$ for deaths related to diabetes, $11 \%$ for myocardial infarction and $13 \%$ for microvascular complications. Any reduction in blood pressure is likely to reduce the risk of complications, with the lowest risk being in those with systolic blood pressure less than $120 \mathrm{mmHg} .^{12}$

An upcoming comprehensive review of global publications on NCD costs from low- and middle-income countries confirms that primary prevention of CVD, stroke and diabetes is far less expensive and has lower unit costs than treatment interventions for these conditions. One way to achieve this is to control hypertension. ${ }^{34}$

The following factors were associated with hypertension among the newly diagnosed diabetics in the bivariate model: age above 40 years, female gender, unemployment, lack of physical exercise, overweight and obesity, increased waist:hip ratios, $\mathrm{LVH}$ and diastolic dysfunction. However after adjusting for possible confounders, only unemployment, gender and increasing BMI were independently associated with hypertension in this model. Among these factors, unemployment and BMI are modifiable, while gender is the non-modifiable factor associated with hypertension.

Attaining and maintaining a healthy weight improves blood pressure and diabetes management, and reduces cholesterol levels. The Trials of Hypertension Prevention (TOHP) study showed that a decrease of $4.4 \mathrm{~kg}$ can lead to a blood pressure reduction of $4 / 3 \mathrm{mmHg} .{ }^{16}$

In a study to determine the prevalence and factors associated with hypertension among residents of the rural district of Rukungiri, Uganda, some of the factors found to be associated with hypertension included: being overweight or obese, female gender and older age. ${ }^{37}$ However all these factors, apart from obesity and being overweight, had no significance in our study in the multivariate model. The reason could be that Wamala et al. ${ }^{37}$ in the earlier study had a bigger sample size compared to ours and enrolled community members, while our population was for newly diagnosed diabetics.

Similar findings have been reported by Wamala and co-workers ${ }^{37}$ and Musinguzi et al. ${ }^{7}$ in other cross-sectional studies. These observations suggest that demographic transition, urbanisation and increasing life expectancy are major determinants of prevalence of hypertension among diabetics. ${ }^{7,4-49}$

In a population-based, cross-sectional survey, Baziel et al. ${ }^{1}$ found further evidence to show that increasing BMI and a waist circumference above the normal range were associated with hypertension. In the same study, sociodemographic factors associated with hypertension included increasing age, male gender, overweight and obesity.

With the substantial burden of hypertension in Uganda coupled with low awareness and limited treatment of hypertension, especially among diabetics, enhanced communitybased education and prevention efforts tailored to addressing modifiable factors are needed. ${ }^{5}$ In our study, participants who were employed were $63 \%$ less likely to have hypertension compared to their unemployed counterparts. One possible explanation would be the lack of physical exercise among the unemployed participants, whereas those who are working often do manual labour in most parts of sub-Saharan Africa.

As observed elsewhere, the prevalence of hypertension increases with increasing age, and the increase is more marked among women than men. ${ }^{33,50}$ We found age above 40 years to be associated with hypertension in the bivariate model, however this level of significance was lost in the multivariate model. With increasing life expectancy, the risk of hypertension becomes very important in sub-Saharan Africa, a region undergoing an epidemiological transition.

In addition patients who had LVH and/diastolic dysfunction were more likely to have hypertension compared to their counterparts without these heart problems. However this was no longer significant at multivariate level. One of the possible explanations could be that hypertension among diabetics caused LVH and diastolic dysfunction, as cited in the ABCD trial and other studies. ${ }^{22}$ Therefore treating hypertension would be one way to prevent these complications because $75 \%$ of all CVD in diabetics can be attributed to hypertension. 
Microalbuminuria was not associated with hypertension in this study, despite the fact that it is one of the major CVD risk factors. Okpere et al., in a cross-sectional study among young people in the community, found contradictory evidence, ${ }^{51}$ but the population they studied was not diabetic.

Type 2 DM and hypertension share several common risk factors, such as physical inactivity and unhealthy diet. Overweight and obesity are potentially amenable to behavioural modification. The benefits of prevention and care extend beyond cardiovascular disease to related conditions of public health importance. They are the focus of efforts to ensure greater prioritisation of NCDs on the global research agenda as well as of development agencies and in the health and development policies of low-income countries.

\section{Limitations}

In the diagnosis of hypertension, we did not perform ambulatory blood pressure monitoring, which is the gold standard, according to guidelines for the diagnosis of hypertension..$^{29}$ This was due to lack of capacity. A non-diabetic control group would have provided better comparison, however in this study we assessed the prevalence and associated factors of hypertension but not its risk factors among diabetics. The recruitment time between June 2014 and January 2015 was relatively short due to limitations in logistics. This could have obscured seasonal differences.

\section{Conclusion}

The prevalence of hypertension was high in this population of newly diagnosed diabetics, who had little knowledge of hypertension, and very few patients were on appropriate treatment. Both modifiable and non-modifiable risk factors were associated with hypertension in this group. Therefore, routine assessment, treatment and control of hypertension among diabetics is necessary to prevent CVD complications and death. Pharmacotherapy should be combined with lifestyle changes to address the modifiable risk factors.

Research reported in this manuscript was supported by the Fogarty International Center of the National Institutes of Health under award number R24TW008861. Dr Mudda was also supported by the Fogarty International Center and the National Heart, Lung, and Blood Institute (NHLBI) at the National Institutes of Health under the Global Health Equity Scholars Consortium at Yale University (D43TW010540). The content is solely the responsibility of the authors and does not necessarily represent the official views of the National Institutes of Health. The authors are grateful to the following persons for their invaluable support: Professors Nelson Sewankambo and Moses R Kamya, the staff of Ward 4B Endocrine, Diabetic Clinic, and the echocardiography and clinical laboratory of Mulago Hospital.

\section{References}

1. Kavishe B, Biraro S, Baisley K, Vanobberghen F, Kapiga S, et al. High prevalence of hypertension and of risk factors for non-communicable diseases (NCDs): a population based cross-sectional survey of NCDS and HIV infection in Northwestern Tanzania and Southern Uganda. BMC Med 2015; 13(126): 126.

2. Twagirumukiza M, de Bacquer D, Kips JG, de Backer G, Stichele RV, van Bortel LM. Current and projected prevalence of arterial hyperten- sion in sub-Saharan Africa by sex, age and habitat: an estimate from population studies. J Hypertens 2011; 29: 1243-1252.

3. Bloomfield GS, Barasa FA, Doll JA, Velazquez EJ. Heart failure in subSaharan Africa. Curr Cardiol Rev 2013; 9: 157-173.

4. Moran AE, Tzong KY, Forouzanfar MH, Roth GA, Mensah GA, Ezzati M, et al. Variations in ischemic heart disease burden by age, country, and income: the Global Burden of Diseases, Injuries, and Risk Factors 2010 study. Glob Heart 2014; 9: 91-99.

5. Kotwani P, Kwarisiima D, Clark TD, Kabami J, et al. Epidemiology and awareness of hypertension in a rural Ugandan community: a crosssectional study. BMC Public Health 2013; 13: 1151.

6. Kearney PM, Whelton M, Reynolds K, Muntner P, Whelton PK, He J. Global burden of hypertension: analysis of worldwide data. Lancet 2005; 365: 217-223.

7. Musinguzi G, Nuwaha F. Prevalence, awareness and control of hypertension in Uganda. PloS One 2013; 8(4): 62236.

8. Maher D, Waswa L, Baisley K, Karabarinde A, Unwin N. Epidemiology of hypertension in low-income countries: a cross-sectional populationbased survey in rural Uganda. J Hypertens 2011; 29: 1061-1068.

9. Maher D, Waswa L, Baisley K, Karabarinde A, Unwin N, et al. Distribution of hyperglycaemia and related cardiovascular disease risk factors in low-income countries: a cross-sectional population-based survey in rural Uganda. Int J Epidemiol 2011; 40: 160-171.

10. Mondo CK, Otim MA, Akol G, Musoke R, Orem J. The prevalence and distribution of non-communicable diseases and their risk factors in Kasese district, Uganda. Cardiovasc J Afr 2013; 24(3): 31-36

11. Wild S, Roglic G, Green A, Sicree R, King H. Global prevalence of diabetes: estimates for 2000 and projections for 2030. Diabetes Care 2004; 27: 1047-1053.

12. Adler AI, Stratton IM, HAW Neil, Yudkin JS. Association of systolic blood pressure with macrovascular and microvascular complications of type 2 diabetes (UKPDS 36): prospective observational study. $\mathrm{Br} \mathrm{Med}$ J 2000; 321: 412-419.

13. Cutler JA. High blood pressure and endorgan damage. $J$ Hypertens 1996; 14(Suppl): 36.

14. Tuomilehto J, Rastenyte D, Birkenhäger WH, Thijs L, Antikainen R, Bulpitt CJ, et al. Effect of calcium channel blockade in older patients with diabetes and systolic hypertension. N Engl J Med 1999; 320: 67784.

15. Sowers J. Recommendations for special populations: diabetes mellitus and the metabolic syndrome. Am J Hypertens 2003; 16(11 pt 2): 41S-45S

16. Makowsky M, Ally PH, Prebtani A, Gelfer M, Manohar A, Jones C. Management of hypertension in people with diabetes mellitus: translating the 2012 Canadian Hypertension Education Program recommendations into practice. Can J Diabetes 2012; 36: 345-353.

17. Dinh W, Lankisch M, Nickl W, Scheyer D, Scheffold T, et al. Insulin resistance and glycemic abnormalities are associated with deterioration of left ventricular diastolic function: a cross-sectional study. Cardiovasc Diabetol 2010; 9: 63.

18. Cooper R, Rotimi C, Ataman S, McGee D, et al. The prevalence of hypertension in seven populations of west African origin. Am J Public Health 1997; 87: 160-168.

19. Kengne AP, Amoah AG, Mbanya J-C. Cardiovascular complications of diabetes mellitus in sub-Saharan Africa. Circulation 2005; 112: 3592-3601.

20. Baba MM, Balogun MO, Akintomide AO, Adebayo RA, Talle MA, et $a l$. Left ventricular geometry in Nigerians with type II diabetes mellitus. Nig Q J Hosp Med 2012; 22(3): 152-157.

21. Somaratne JB, Whalley GA, Poppe KK, ter Bals MM, Wadams G, et al. Screening for left ventricular hypertrophy in patients with type 2 diabetes mellitus in the community. Cardiovasc Diabetol 2011; 10: 29. 
22. Havranek E, Esler A, Estacio RO, Mehler PS, Schrier RW. Differential effects of antihypertensive agents on electrocardiographic voltage: results from the Appropriate Blood Pressure Control in Diabetes (ABCD) trial. Am Heart J 2003; 145(6): 993-998.

23. Keil JE, Sutherland SE, Knapp RG, Lackland DT, Gazes PG, Tyroler HA. Mortality rates and risk factors for coronary disease in black as compared with white men and women. N Engl J Med 1993; 329: 738.

24. Collins R, Peto R, MacMahon S, Herbert P, Fiebach N, Eberlein K, et al. Blood pressure, stroke, and coronary heart disease. Lancet 1990; 335: $827-838$.

25. Lawes CM, van der Hoorn S, Rodgers A. Global burden of bloodpressure related disease, 2001. Lancet 2008; 371: 1513-1518.

26. Yach D, Hawkes C, Gould CL, Hofman KJ. The global burden of chronic diseases: overcoming impediments to prevention and control. $J$ Am Med Assoc 2004; 291: 2616-2622.

27. Lim SS, Vos T, Flaxman AD, Danaei G, Shibuya K, Adair-Rohani H, et al. A comparative risk assessment of burden of disease and injury attributable to 67 risk factors and risk factor clusters in 21 regions, 1990-2010: a systematic analysis for the Global Burden of Disease Study 2010. Lancet 2012; 380: 2224-2260.

28. Daskalopoulou SS, Rabi DM, Prebtani A, et al. The 2015 Canadian Hypertension Education Program recommendations for blood pressure measurement, diagnosis, assessment of risk, prevention, and treatment of hypertension. Can J Cardiol 2015; 31: 549-568.

29. Mensah GA. Epidemiology of stroke and high blood pressure in Africa Heart 2008; 94: 697-705.

30. Opie LH, Seedat YK. Hypertension in sub-Saharan African populations. Circulation 2005; 112: 3562-3568.

31. Addo J, Smeeth L, Leon DA. Hypertension in sub-Saharan Africa: a systematic review Hypertension 2007; 50: 1012-1018.

32. Lang RM, Bierig M, Devereux RB, Flachskampf FA, Foster E, Pellikka $\mathrm{PA}$, et al. Recommendations for chamber quantification: A report from the American Society of Echocardiography's Guidelines and Standards Committee and the Chamber Quantification Writing Group, developed in conjunction with the European Association of Echocardiography, a branch of the European Society of Cardiology. J Am Soc Echocardiogr 2005; 18: 1440-1463.

33. Drawz PE, Abdalla M, Rahman M. Blood pressure measurement: clinic, home, ambulatory, and beyond. Am J Kidney Dis 2012; 60(3): 449-462.

34. Schwartz JI, Guwatudde D, Nugent R, Kiiza KM. Looking at noncommunicable diseases in Uganda through a local lens: an analysis using locally derived data. Glob Health 2014; 10: 77.

35. Mayega RW, Makumbi F, Rutebemberwa E, Peterson S, Ostenson CG Tomson G, et al. Modifiable socio-behavioural factors associated with overweight and hypertension among persons aged 35 to 60 years in eastern Uganda. PLoS One 2012; 7: e47632.

36. Mayega RW, Guwatudde D, Makumbi FE, Nakwagala FN, Peterson $\mathrm{S}$, Tomson $\mathrm{G}$, et al. Comparison of fasting plasma glucose and haemoglobin Alc point-of-care tests in screening for diabetes and abnormal glucose regulation in a rural low income setting. Diabetes Res Clin Pract
2014; 104: 112-120.

37. Wamala J, Karyabakabo Z, Ndungutse D, Guwatudde D. Prevalence factors associated with hypertension in Rukungiri District, Uganda - A community-based study. Afr Health Sci 2009; 9: 153-160.

38. Damasceno A, Azevedo A, Siva matos C, Prista A, Diogo D, et al. Hypertension prevalence, awareness, treatment, and control in Mozambique (urban/rural gap during epidemiological transition). Hypertension 2009; 54: 77-83.

39. Agyemang C, Bruijnzeels MA, Owusu-Dabo E. Factors associated with hypertension awareness, treatment, and control in Ghana, West Africa. J Hum Hypertens 2005; 20: 67-71.

40. Pereira M, Lunet N, Azevedo A, Barros H. Differences in prevalence, awareness, treatment and control of hypertension between developing and developed countries. J Hypertens 2009; 27: 963-975.

41. Tumwesigye E, Wana G, Kasasa S, Muganzi E, Nuwaha F. High uptake of home-based, district-wide, HIV counseling and testing in Uganda. AIDS Patient Care STDS 2010; 24: 735-741.

42. Menzies N, Abang B, Wanyeze R, Nuwaha F, Mugisha B, et al. The costs and effectiveness of four HIV counselling and testing strategies in Uganda. AIDS Patient Care STDS 2009; 23: 395-401.

43. Kibirige D, Atuhe D, Sebunya R, Mwebaze R. Suboptimal glycaemic and blood pressure control and screening for diabetic complications in adult ambulatory diabetic patients in Uganda: a retrospective study from a developing country. J Diabetes Metab Dis 2014; 13: 40.

44. Psaltopoulou T, Orfanos P, Naska A, Lenas D, Trichopoulos D, et al. Prevalence, awareness, treatment and control of hypertension in a general population sample of 26913 adults in the Greek EPIC study. Int $J$ Epidemiol 2004; 33: 1345-1352.

45. Dzudie A, Kengne AP, Muna WF, Ba H, Menanga A, et al. Prevalence, awareness, treatment and control of hypertension in a self-selected subSaharan Africa urban population: a cross-sectional study. $\mathrm{Br}$ Med J Open 2012; 2: 2012-001217.

46. Reisin E, Harris RC, Rahman M. Commentary on the 2014 BP guidelines from the panel appointed to the Eighth Joint National Committee (JNC 8). J Am Soc Nephrol 2014: ASN. 2014040371.

47. Walker R, Whiting D, Unwin N, Mugusi F, Swai M, et al. Stroke incidence in rural and urban Tanzania: a prospective, community-based study. Lancet Neurol 2010; 9: 786-792.

48. Walker RW, McLarty DG, Kitange HM, Whiting D, Masuki G, et al. Stroke mortality in urban and rural Tanzania. Lancet 2000; 355: 1684-1687.

49. Lopez AD, Mathers CD, Ezzati M, Jamison DT, Murray CJL. Global Burden of Disease and Risk Factors. New York: The World Bank and Oxford University Press, 2006.

50. Wild S, Roglic G, Green A, Sicree R. King. Global prevalence of diabetes: estimates for 2000 and projections for 2030. Diabetes Care 2004; 20: 1047-1053.

51. Okpere AN, Anochie IC, Eke FU. Prevalence of microalbuminuria among secondary school children. Afr Health Sci 2012; 12(2): 140-147. 